\title{
NUMERICAL INVESTIGATION ON THE PERFORMANCE OF TRANSONIC AXIAL COMPRESSOR WITH THE SLOTTED BLADE
}

\author{
Aksorn-In DHANUPORN \\ School of Energy and Power Engineering, \\ Xi'an Jiaotong University \\ dhanuporn.a@gmail.com \\ Xian, Shaanxi, China \\ Yang ZHAO \\ School of Energy and Power Engineering, \\ Xi'an Jiaotong University \\ Xian, Shaanxi, China
}

\author{
Yali CHEN \\ School of Energy and Power Engineering, \\ Xi'an Jiaotong University \\ Xian, Shaanxi, China \\ Zhongguo SUN \\ School of Energy and Power Engineering, \\ Xi'an Jiaotong University \\ Xian, Shaanxi, China
}

\begin{abstract}
The stable operating range is one of the key performance parameters on safety for general compressors. In order to improve the stable range, the flow control technique by slotted rotor was computationally studied and investigated based on the case of well-known transonic axial compressor (NASA Rotor 67). The principle of slotted blade is that the rotor blade is manufactured with the aim to have a slot (connecting between pressure side and suction side) at designed location. Then, the fluid is able to flow from pressure side to suction side by the pressure differences. This effect could literally energize the mainstream flow including the retarded flow caused by the aerodynamic losses. As a result, the operating range of compressor would be improved. Throughout this work, the action mechanism of the slot and the impact on compressor performance were analyzed by the prominent commercial software, NUMECA/EURANUS. The slot was located at three significant areas (e.g., leading edge, midchord, and trailing edge). Moreover, it was also located relative to the axial tip chord of the rotor blade. The stability improvement and the modified performance of the investigated compressor (e.g., pressure ratio and efficiency) were evaluated and compared with those of original blade. The location of slot giving the best improvement was finally identified. Afterwards, the optimum location would be selected for the further investigation by orienting the slot to be inclined configuration. In addition, the geometry of slot would be changed to nozzle as well for high velocity flow at the exit in order to gain more energization (more improvement).
\end{abstract}

\section{INTRODUCTION}

Currently, transonic axial compressors have commonly been used in commercial aircraft as a core component of propulsion system. It is an important part because the first of the whole processes originates in this stage (compressing the working fluid). Moreover, compressors used in aircraft engine normally operate over a wide range of working loads. Therefore, it must be carefully and well designed with an adequate safety margin. Even though it is designed for efficient operation during the longest use (cruising), it must be safe as well for the others (e.g., taking off, landing, and changing in its altitude). Hence, to avoid the possible and also impossible accidents, axial compressors must operate safely at all times.

Stability improvement of axial compressors can be achieved by using the flow control techniques to energize the flow through the flow passage. As a result, flow separation or stall occurrence can be delayed (Lord et al., 2000), increasing in stable operating range. Basically, there are two types of flow control techniques divided by external work requirement, which are actuator (requiring additional devices such as synthetic jets and bleed techniques) and geometric configuration (not required external work input such as casing treatment and slotted rotor). While the geometric configurations seems to be most available in use for the industrial in nowadays (Hu et al., 2019).

Even though the use of casing treatments could provide good improvement of compressor stability, it also has unavoidable side effects such as efficiency loss and additional weight for modified configurations (Fujita and Takata, 1984; Pérez Flores et al., 2008; Weichert et al., 2011). Therefore, 
the slotted rotor would be selected in this work. Moreover, the available application of slot could be daily found in the highlift device on the trailing edge of an aircraft wing (flaps).

A flow control technique without additional weight and easier for manufacturing processes (by machining the slot onto the blade) is slotted rotor. The principle of slotted rotor is that the rotor blade is machined to make a hole (creating the flow tunnel between the pressure side and the suction side). Once the slot is applied, the fluid is able to flow from the pressure side through the suction side naturally by pressure differences. Thus, the retarded flow through the flow passage would be energized which would result in larger stable operating range.

Firstly, the application and mechanism of slotted rotor is similar to tandem cascades. For tandem cascades, there are two number of blades in a row called front blade and rear blade. It would be placed consecutively thus creating a full span gap to energize the separated flow (Sakai et al., 2003).

The slot technique was first experimentally investigated by (Rockenbach, 1968). The impact of slots showed a small improvement of stable operating range. It provided a good performance when the slot was located at mid-span region. In contrast, it showed a low performance when the slot was located at near end-wall regions. (Ramzi and AbdErrahmane, 2013) investigated the impact of slot location, slot width, and its slopes on both 2D and 3D. The results from 2D simulations showed that the maximum in loss coefficient reduction was $28 \%$ and the improvement of flow turning angle was 5 degrees. Whilst 3D simulations' results indicated that the advantage of slot was to slow down the boundary layer separation on blade suction surface and eliminate corner stall. (Jain et al., 2015) numerically studied the feature of the slotted rotor (slot location and its geometry on the performance of NASA Rotor 37) from six models of slot. The results clearly showed that all six slot models tended to increase the stall margin with a slight reduction in both pressure ratio and efficiency. Maximum improvement in stall margin was $3.2 \%$ when slot was located at near to mid-chord region. Furthermore, with the concerns about structural problems, numerical analysis was also executed in Jain's work. Maraging steel 200 was selected for material of blade. The results showed that the stress in case of slotted rotor was below the standard yield stress of the blade's material. Therefore, there were no structural problems with slotted blade. (Borra and Alone, 2015) investigated the slot technique on the stall margin improvement of single stage transonic axial compressor. Six locations with the same slot configuration were numerically simulated to find the optimum location. The results indicated that the optimum location of slot was at near trailing edge. Moreover, this work also showed the further improvement by selecting the two effective positions of slot and oriented in inclined position. (Liu et al., 2016) using flow control technique to eliminate corner separation in compressor cascade by machining the slot at blade root. The results evidently showed a positive effect on compressor performances caused by corner separation reduction. Corner separation was also found to be suppressed by slot technique in the numerical study by (Hu et al., 2019).
Therefore, this method, slotted rotor, clearly justifies itself to be an effective way to improve the compressor stability. But the answer for the right place to locate the slot onto the rotor blade still be unclear whether it should be located at near mid-chord or near leading edge based on the results from the aforementioned works. Then, the slot would be located at three main locations (20\% for near leading edge, $40 \% 50 \%$ and $60 \%$ for near mid-chord, and $80 \%$ for near trailing edge) to find the optimum location in this work. Moreover, the location of the slots giving the best improvement would be selected for further investigation by orienting the slot inclined relative to the axial tip chord and changing the slot geometry from square to nozzle in order to gain more improvement by increasing the exit velocity.

\section{DETAILED SPECIFICATION OF COMPRESSOR}

The compressor model, transonic axial compressor, used in the present study for numerical investigation was NASA Rotor 67. Its appearance was shown in Figure 1.

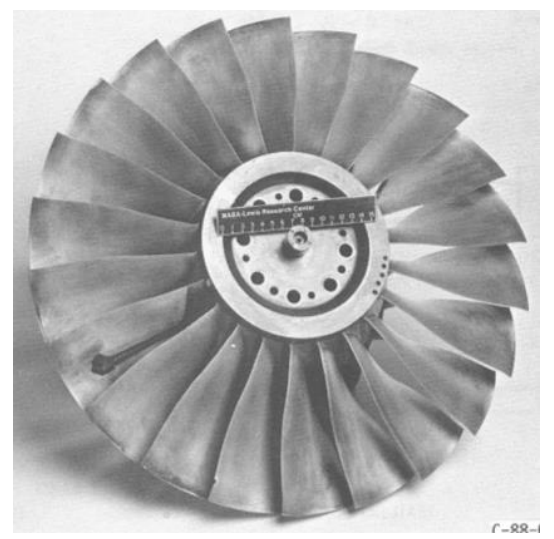

Figure 1 Transonic compressor NASA Rotor 67

Rotor 67 is well-known as a low aspect ratio type of compressor. The rotor has 22 number of blades with the aspect ratio of 1.56 (calculated from the average span divided by root axial chord). For the other parameters at design operating point, it has 1.63 in terms of pressure ratio, $33.25 \mathrm{~kg} / \mathrm{sec}$ for mass flow rate and 16,043 rpm for rotational speed. The main characteristics are tabulated in Table 1. The other specifications can be found in experimental data of (Strazisar et al., 1989) measured by laser anemometer.

Table. 1 Detailed specification of NASA Rotor 67

\begin{tabular}{|l|c|}
\hline Number of blades & 22 \\
\hline Rotational speed $(\mathrm{rpm})$ & 16,043 \\
\hline Design mass flow rate $(\mathrm{kg} / \mathrm{s})$ & 33.25 \\
\hline Pressure ratio & 1.63 \\
\hline Design tip clearance $(\mathrm{mm})$ & 1.016 \\
\hline Inlet tip relative Mach number & 1.38 \\
\hline Rotor tip speed $(\mathrm{m} / \mathrm{s})$ & 429 \\
\hline Inlet tip diameter $(\mathrm{mm})$ & 514 \\
\hline Exit tip diameter $(\mathrm{mm})$ & 485 \\
\hline
\end{tabular}




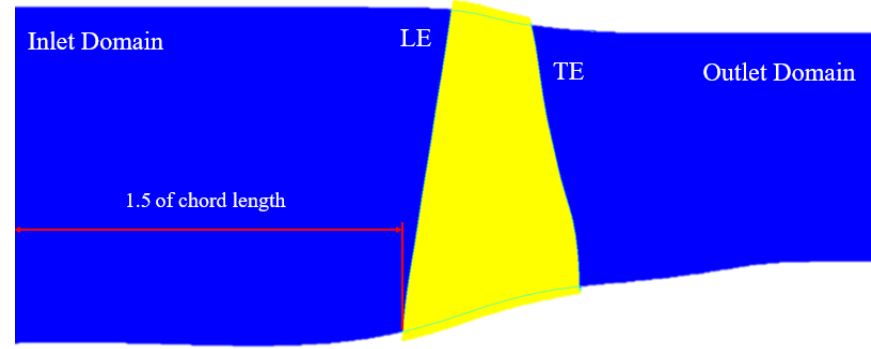

Figure 2 Computational domain with extended inlet

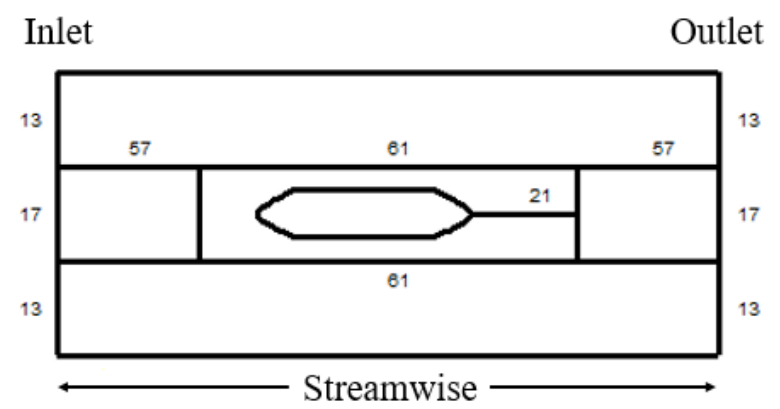

Figure 3 Grid topology for rotor passage

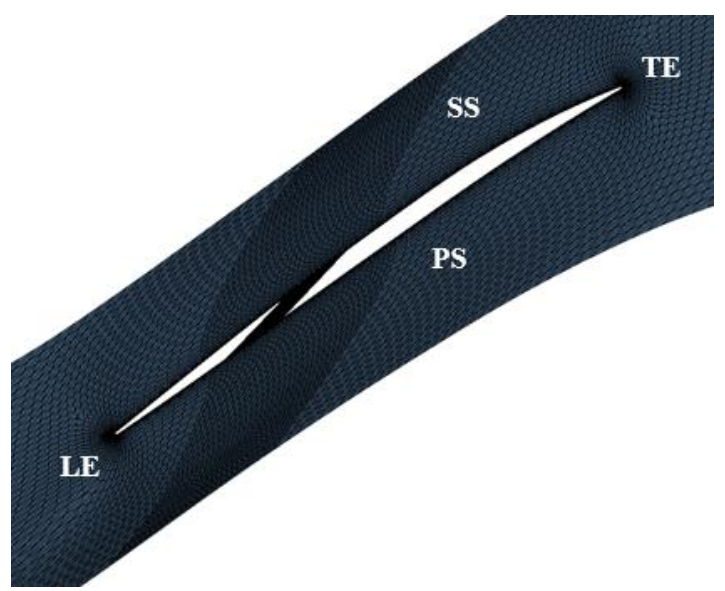

Figure 4 Additional mesh near to slot inlet and outlet

\section{NUMERICAL METHOD}

AutoGrid5 was used to generate computational model of Rotor 67. Single blade passage was highly considered in order to stay away from the tremendous requirements by the computational calculation system (Borra and Alone, 2015). For flow stability, only the length of inlet domain was extended approximately 1.5 times to chord length shown as 2D in Figure 2.

Grid topology setting were shown in Figure 3 . The grids in streamwise direction have 175 points $(57 \times 61 \times 57)$. While the grids at boundary regions, inlet and outlet, have 43 points $(13 \times 17 \times 13)$. Baseline model, rotor blade without slot, was created first in order to ease for the slotted models by just creating an individual block of slot onto the baseline. The number of grid for a single passage of baseline model was 755,819 with $1,835.1$ of minimum aspect ratio and 2.12 of maximum expansion ratio.
To clearly capture the flow behavior near to the slot, the number of grid was added more in the vicinity of both inlet and outlet of slot as shown in Figure 4.

The simulation tasks were accomplished by commercial software, NUMECA/EURANUS. Turbulent Navier-Stokes was selected for Mathematical model. Moreover, the acquisition of the reasonable results also directly derives from suitable turbulence models. Hence, the turbulence model must be selected carefully because it has high impact on the predicted performances. (Spotts and Gao, 2016) numerically investigated six turbulence models for transonic axial compressor's simulation. Furthermore, NASA Rotor 67 was used as a computational model in this investigation. The results showed that the Spalart-Allmaras model (SA) and the Shear Stress Transport model (SST) could converge to near stall point and provide the reasonable results. According to the available research works (Zheng et al., 2010; Zhou et al., 2017) based on NASA Rotor 67's simulation by NUMECA/EURANUS. The Spalart-Allmaras was used most as a turbulence model. As a result, the Spalart-Allmaras (SA) was selected for the turbulence model in this work. However, the predicted results by SA would be compared to SST and KEpsilon, and presented in validation topic.

Both pressure and temperature at standard sea level, 101,325 Pa and 288.15 K, were imposed as inlet boundary conditions. At the same time, static pressure was selected as outlet boundary condition.

Lastly, the simulation was started calculating from choke point to stall point by increasing the static back pressure as $1,000 \mathrm{~Pa}$ in each calculation. For high accuracy, mass flow imposed was prescribed instead of pressure imposed when simulation was being executed at near stall point by decreasing $0.01 \mathrm{~kg} / \mathrm{s}$ in each step. Simulation would stop at the highest pressure ratio point as a stability limit. Because pressure ratio would decrease while mass flow is decreasing after the peak point as a result of stall occurrence.

\section{DESIGN CRITERIA OF SLOT}

(Borra and Alone, 2015) decided to locate the slot near to blade tip in order to get the highest benefit from the maximum blade loading. Therefore, flow analysis of baseline model was carried out in order to identify the area of high blade loading at near stall condition.

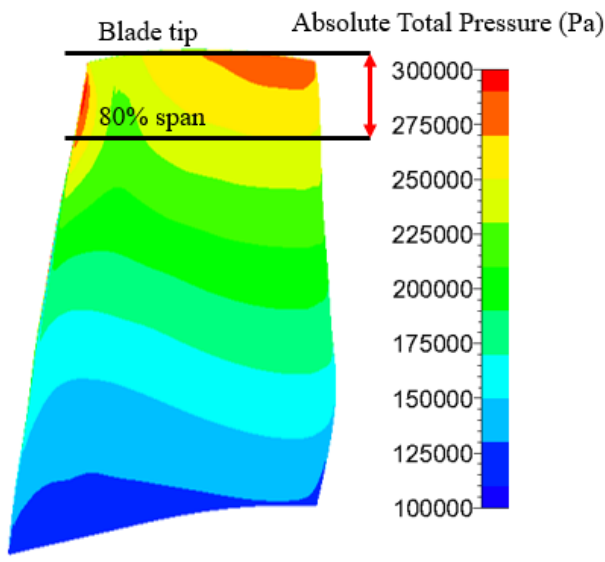

Figure 5 Region of high pressure 
According to the observation of absolute total pressure on pressure surface of baseline model, it showed that from $80 \%$ span to blade tip was found to be the length of the high blade loading as shown in Figure 5. Based on the foregoing criteria, the slot length was designed as $15 \%$ of blade length, locating from $80 \%$ to $95 \%$ span. For the other dimensional details, it was tabulated in Table 2.

Table. 2 Slot dimension

\begin{tabular}{|c|c|}
\hline \multicolumn{2}{|c|}{ DIMENSION OF SLOT } \\
\hline Length & $15 \%$ of blade length \\
\hline Width & $2 \mathrm{~mm}$ \\
\hline Depth & $\begin{array}{c}\text { straight through the blade } \\
\text { (pressure to suction side) }\end{array}$ \\
\hline
\end{tabular}

\section{NUMERICAL METHOD VALIDATION}

\section{Validation of Predicted Results}

The validation of predicted results would be carried out in order to ensure that the results derived from simulation are in good agreement with the experiment, the simulation can capture the flow behaviors correctly.

According to the validation of overall performance in Figure 6, all the predicted results from three different turbulence models (e.g., SA, SST, and K-Epsilon) seemed lower than the experiment. However, the trends of overall performance from both pressure ratio validation and efficiency validation were as similar as the experiment.

Actually, there was a gap found in this work between experiment and simulation. However, this gap could be frequently found in the other research works as well (Adamczyk et al., 1991; Zhou et al., 2017).

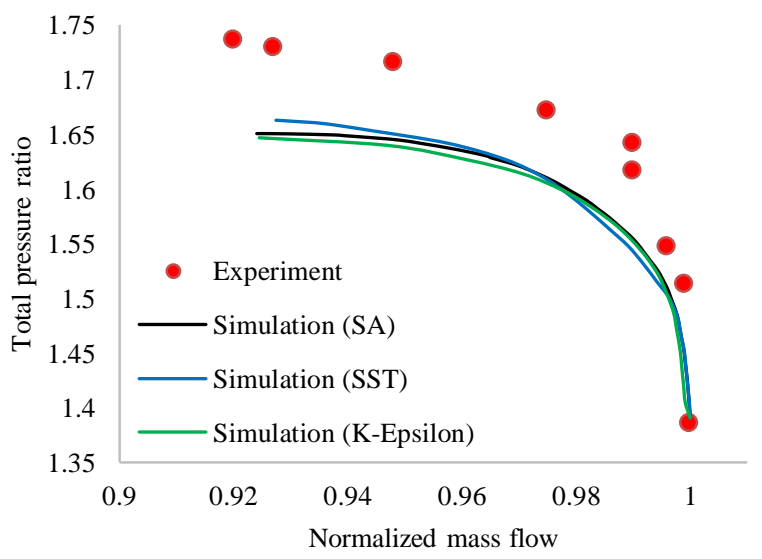

(a) Comparison of pressure ratio

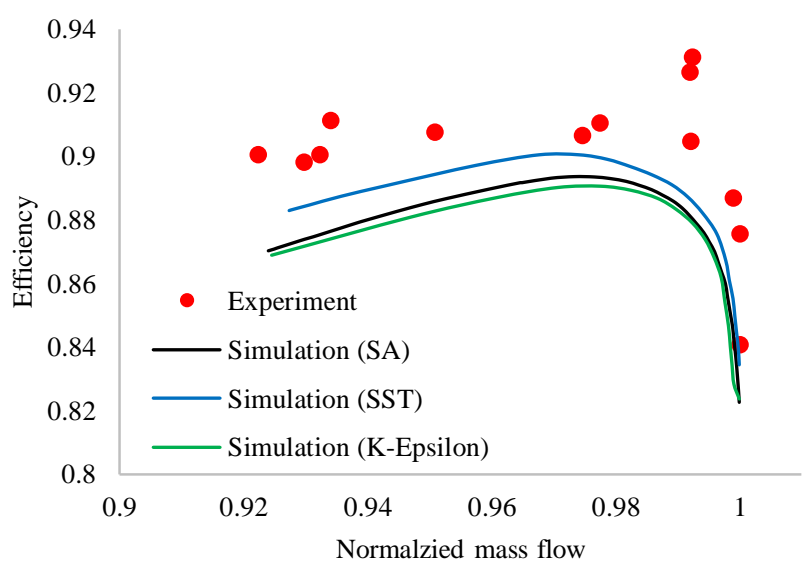

(b) Comparison of efficiency

Figure 6 Validation of predicted performance

\section{Validation of Turbulence Models}

To check the accuracy of turbulence model. The predicted performance from Spalart-Allmaras (SA) was compared with the results from Shear Stress Transport (SST) and K-Epsilon models as shown in Figure 6.

According to the validation of both pressure ratio and efficiency from these three turbulence models, the overall performance from K-Epsilon was the lowest compared to SA and SST. At the same time, the results from SST turbulence model could give the highest values to the overall predicted efficiency. But its normalized mass flow at near stall point was shorter than SA. The normalized mass flows from SA, SST, $\mathrm{K}$-Epsilon, and experiment were tabulated in Table 3.

Table. 3 Normalized flow at near stall point

\begin{tabular}{|c|c|}
\hline The normalization of mass flow at near stall point \\
\hline Experiment & 0.921 \\
\hline SA & 0.924 \\
\hline SST & 0.927 \\
\hline K-Epsilon & 0.9245 \\
\hline
\end{tabular}

SA model could give the normalized mass flow at near stall point close to the experiment. Moreover, the overall performances, pressure ratio and efficiency, from SA model looked better than the others. Although, the predicted results from K-Epsilon also showed a good prediction for the value of normalized flow at near stall point, but its overall performance was even lower than SA model. Therefore, SA model was found to be the best choice for suitable turbulence model in this work based on the foregoing criteria.

\section{RESULTS AND DISCUSSION}

In the present work, slot based on three main locations (e.g., $20 \%$ of tip chord as near leading edge, $40 \%, 50 \%$ and $60 \%$ as near mid-chord, and $80 \%$ as near trailing edge) were picked up to study its impact on the performance of NASA Rotor 67. 
The improvement in stall margin and the change in pressure ratio and efficiency were mathematically calculated based on the following equations (Borra and Alone, 2015).

Stall margin improvement (\%):

$$
=\quad \frac{\mathrm{m}_{\text {stall,nr }}-\mathrm{m}_{\text {stall,sr }}}{\mathrm{m}_{\text {stall,nr }}} \times 100
$$

Change in pressure ratio at design point $(\%)$ :

$$
=\quad \frac{P_{\text {design,nr }}-P_{\text {design }, \mathrm{sr}}}{\mathrm{Pr}_{\text {design }, \mathrm{nr}}} \times 100
$$

Change in efficiency at design point $(\%)$ :

$$
=\quad \frac{E_{\text {design,nr }}-E_{\text {design, sr }}}{E_{\text {design,nr }}} \times 100
$$

According to the performance curves in Figure 9-10, it clearly showed that the stability, stall margin, was found to be improved for any locations by this slot configuration. In contrast, the performances of the compressor, pressure ratio and efficiency, were decreased compared to the baseline, more or less might be depended on where the slot was. The quantities of the improvement were tabulated in Table 4 , calculating from the above equations.

Even though the improvement of stall margin was possibly found from any locations of slot, but the largest improvement obtained when there was a slot at $40 \%$ of tip chord, $1.976 \%$. The largest decrement in terms of pressure ratio and efficiency was in the case of slot at $50 \%$ of tip chord. Based on this slot configuration, the improvement was the smallest when there was a slot at $80 \%$ of tip chord, near trailing edge. Therefore, the slot at $40 \%$ of tip chord would be chosen as the optimum location for further study.

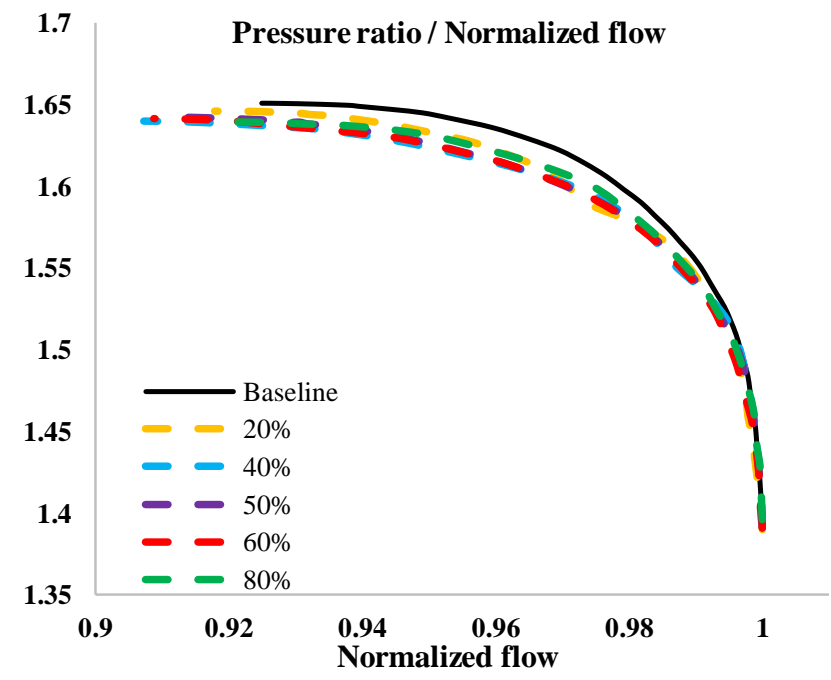

Figure 9 Pressure ratio versus normalized flow of baseline, $20 \%, 40 \%, 50 \%, 60 \%$ and $80 \%$ at design speed

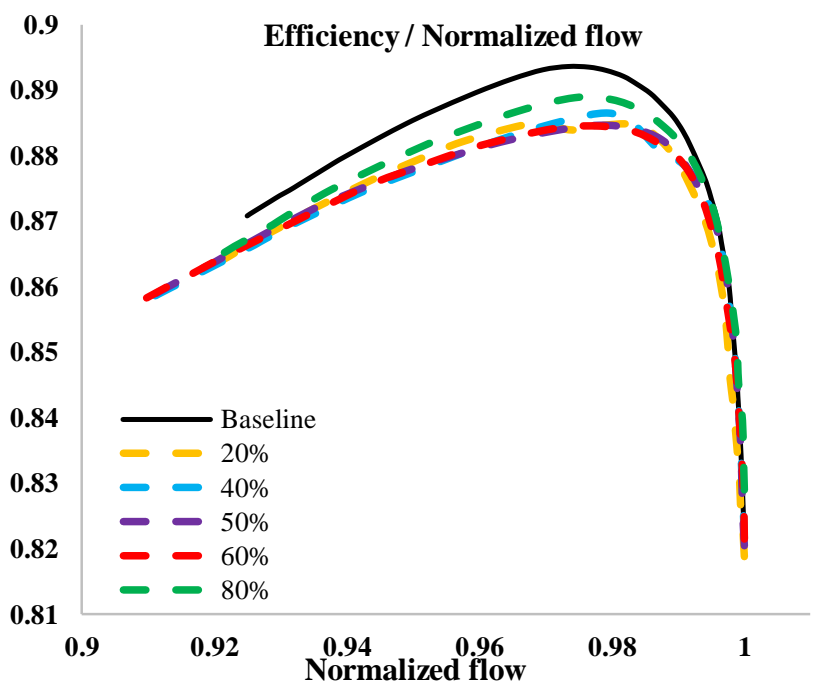

Figure 10 Efficiency versus normalized flow of baseline, $20 \%, 40 \%, 50 \%, 60 \%$ and $80 \%$ at design speed

Table. 4 Percentage of change in stall margin and performances at design point

\begin{tabular}{|c|c|c|c|}
\hline Location & Stall Margin & Pressure Ratio & Efficiency \\
\hline $20 \%$ & $+1.035 \%$ & $-1.226 \%$ & $-0.773 \%$ \\
\hline $40 \%$ & $+1.976 \%$ & $-1.288 \%$ & $-0.964 \%$ \\
\hline $50 \%$ & $+1.725 \%$ & $-1.349 \%$ & $-1.042 \%$ \\
\hline $60 \%$ & $+1.756 \%$ & $-1.288 \%$ & $-0.986 \%$ \\
\hline $80 \%$ & $+0.595 \%$ & $-0.920 \%$ & $-0.571 \%$ \\
\hline
\end{tabular}

*Note: (+): improvement, (-): reduction for the observed parameters

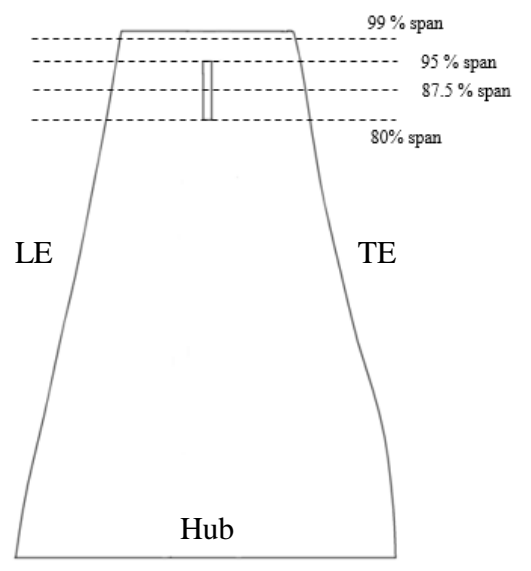

Figure 11 Locations of observation point.

Flow analysis was then executed in terms of Mach number. The relative Mach number contours between design point and stall point of baseline rotor were presented in Figure 12-13. Moreover, only four significant locations were selected to investigate the impact of slot as shown in Figure 11.

According to Figure 12, Mach number contours showed the smooth flow through the flow passage under design operating point at $80 \%, 87.5 \%$, and $95 \%$ span. While the accumulation of low energy fluid was initially found at near end-wall region, $99 \%$ span. 
$80 \%$ span

$87.5 \%$ span

$95 \%$ span

$99 \%$ span
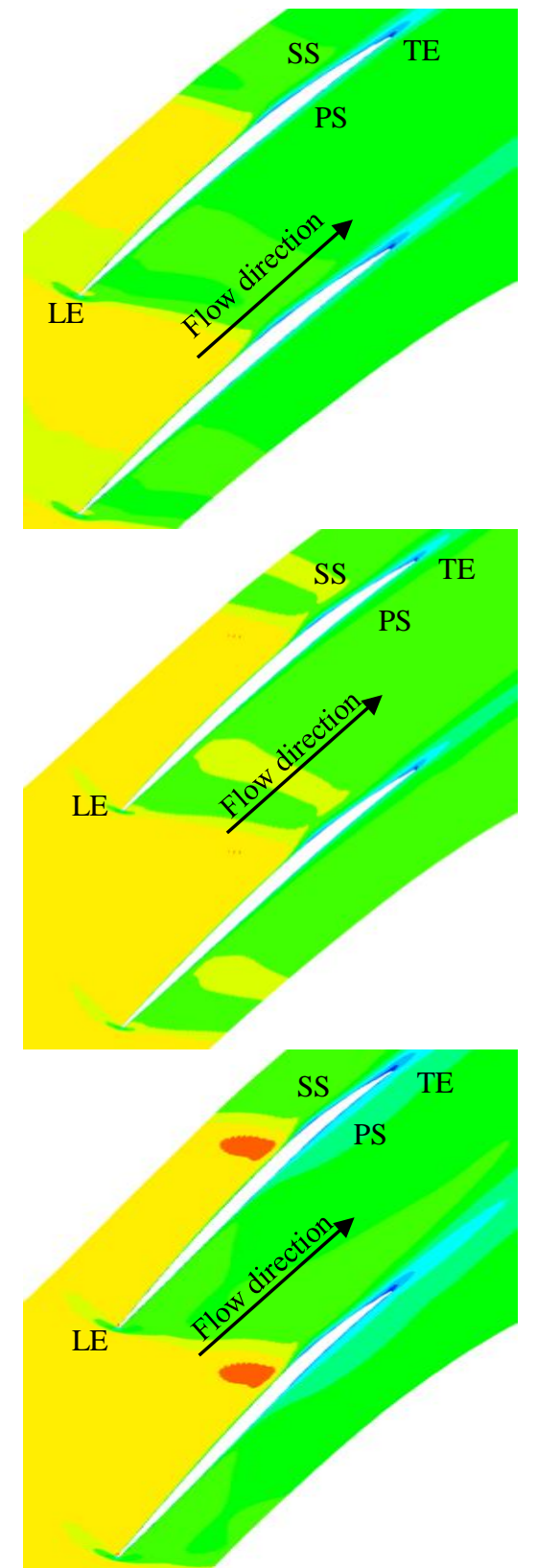
PS

$\mathrm{SS}$ TE

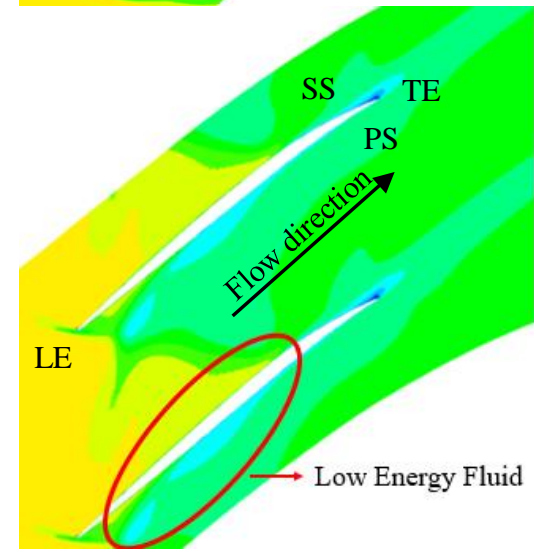

Figure 12 Relative Mach contours at design point of baseline model at $80 \%, 87.5 \%, 95 \%$, and $99 \%$ span
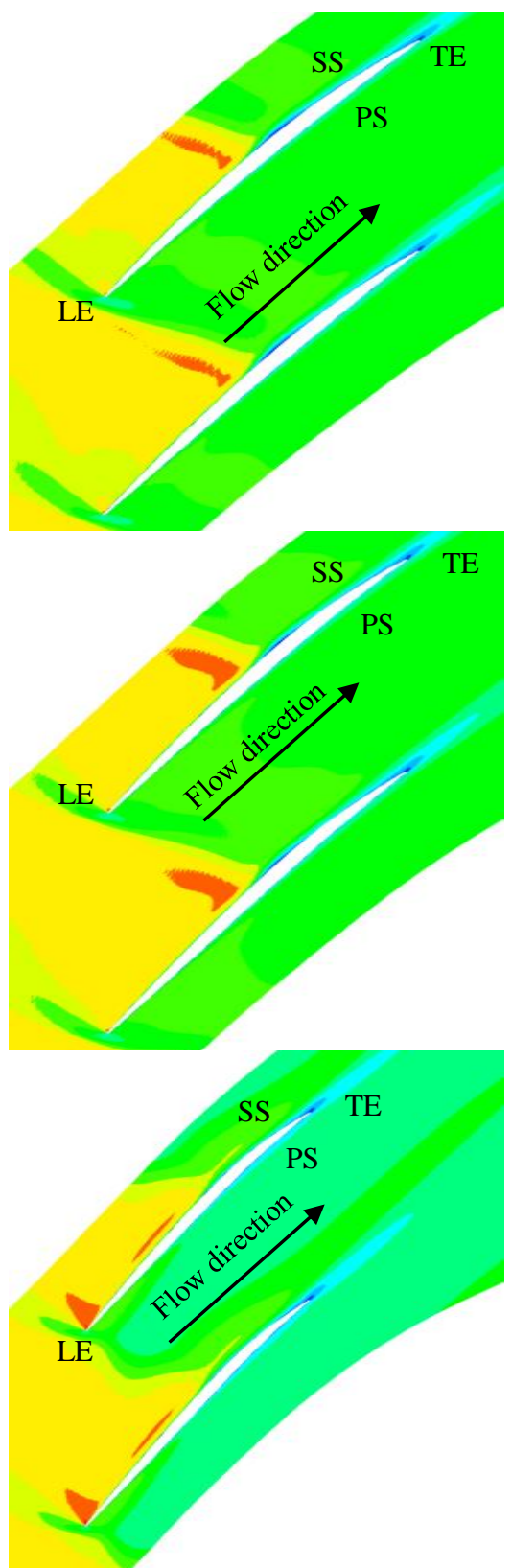

Relative Mach Number

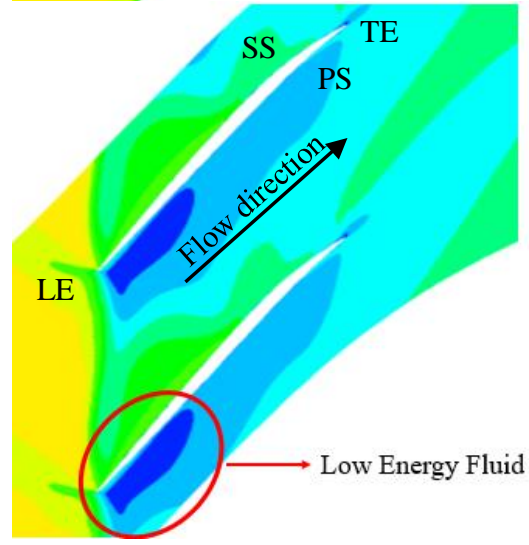

Figure 13 Relative Mach contours at stall point of baseline model at $80 \%, 87.5 \%, 95 \%$, and $99 \%$ span 
$80 \%$ span

$87.5 \%$ span

$95 \%$ span

$99 \%$ span
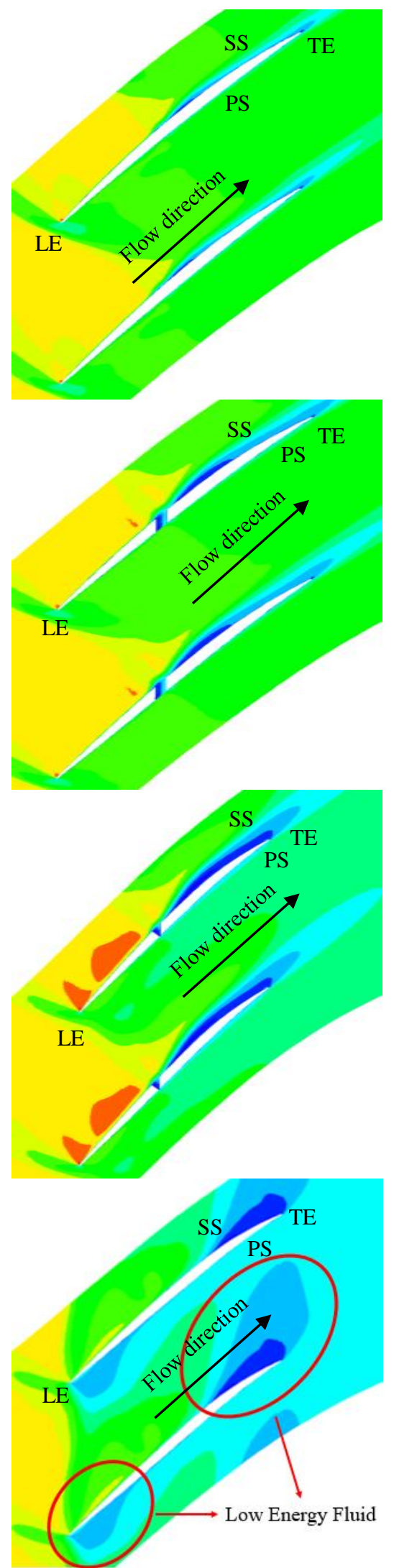

Figure 14 Relative Mach contours at stall point of straight slot at $80 \%, 87.5 \%, 95 \%$, and $99 \%$ span
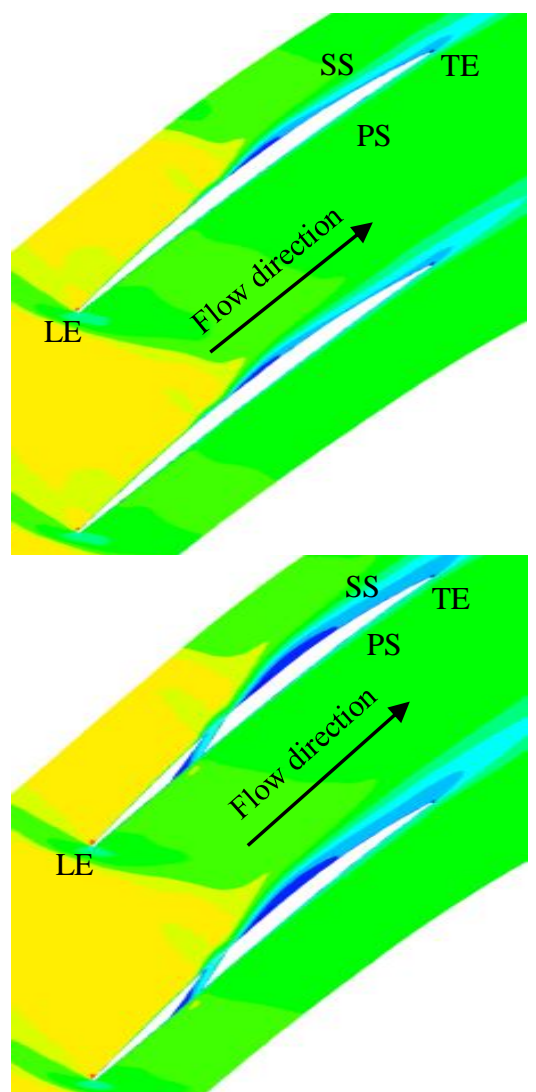

Relative Mach Number
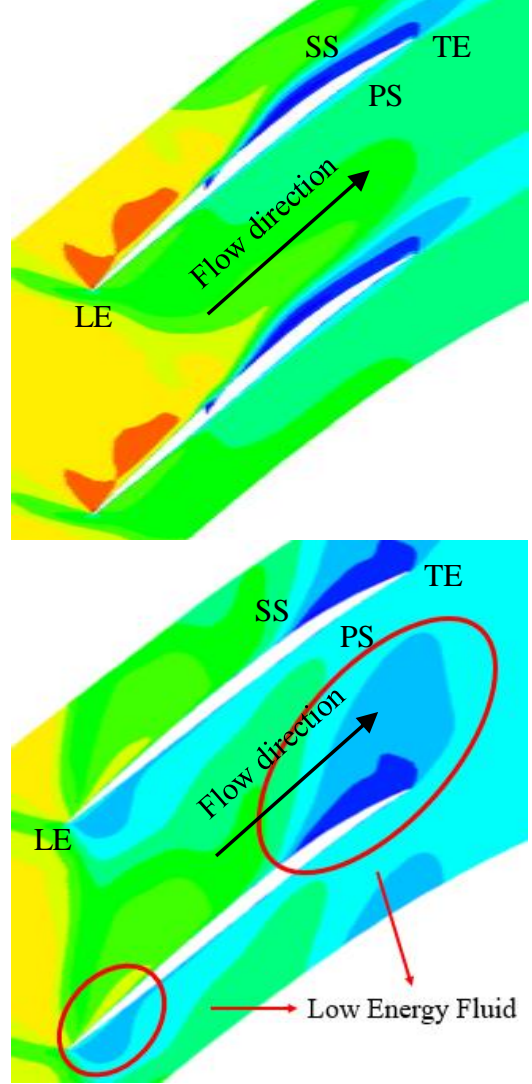

Figure 15 Relative Mach contours at stall point of inclined slot at $80 \%, 87.5 \%, 95 \%$, and $99 \%$ span 
For the stall operating point of baseline rotor, the large area of low energy fluid (also known as flow blockage) could be clearly seen at $99 \%$ span, near to tip chord and end-wall region, as shown in Figure 13. This phenomenon could influence the mainstream flow. As a result, the mainstream flow would loss its momentum (reduction of its axial velocity). Finally, aerodynamic instabilities would occur and lead to stall.

Flow analysis was further analyzed by comparing the relative Mach number contours of baseline rotor with slotted rotor (rotor with slot at $40 \%$ tip chord) under the near stall operating point. According to Figure 14, the large area of low energy fluid at $99 \%$ span could be largely eliminated compared to baseline rotor. As a result, the compressor with slotted rotor could be further operated before encountering the stall occurrence. However, when the slot was applied on this rotor, it also showed the side effect by creating the flow separation on downstream of suction surface as shown in Figure 14 (87.5\% span, 95\% span, and 99\% span). The onset of downstream flow separation at near tip chord could be explained by Figure 16. According to Figure 16 (a), the flow from slot (red lines) would be moved upwards to blade tip under the influence of surface streamlines (green lines). Next, the deviated flow would interact with tip leakage flow (white lines) at downstream of blade tip thus creating the high disorder zone shown in Figure 16 (b). As a result, the boundary layer separation or flow separation would be originated.

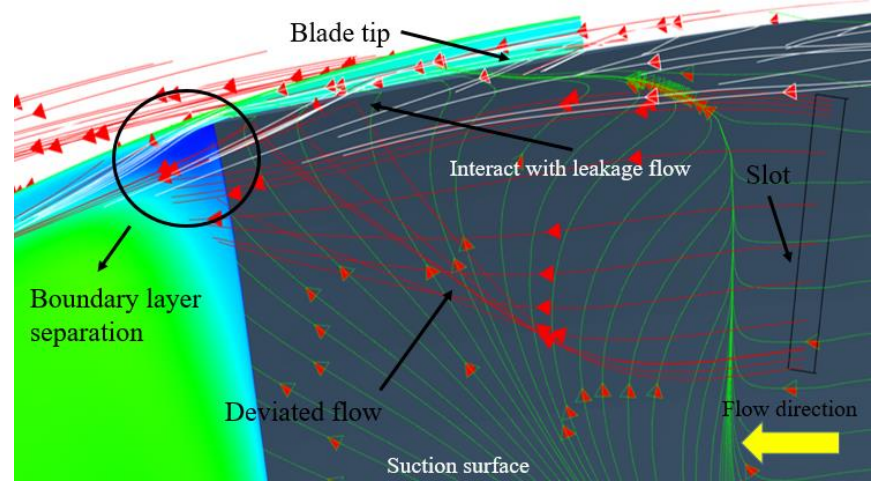

(a) Front view on suction surface

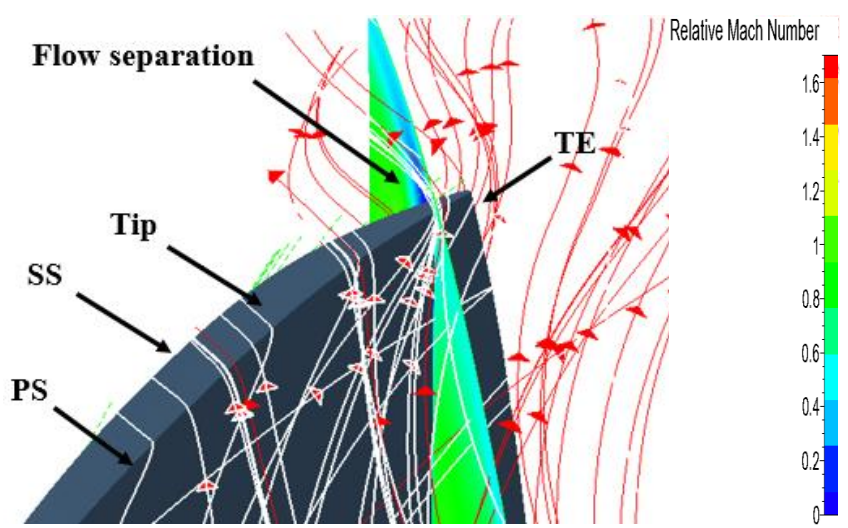

(b) Top view

Figure 16 The onset of flow separation
Next, the impact of inclined slot would be investigated. Moreover, the nozzle configuration would also be applied with the aim to gain more improvement if the slot can provide higher velocity flow.

\section{Inclined slot}

The inclined configuration was created based on the optimum slot location. According to the previous investigation, the slot at $40 \%$ tip chord was chosen for the slot outlet position on suction surface. Because it could provide the largest improvement when there was a jet flow from this position. Moreover, the inlet of slot should be located before $40 \%$ for inclined configuration. Hence, $20 \%$ of tip chord was chosen for the inlet position on pressure surface. While the slot length was kept constant to the previous investigation as $15 \%$ of blade length. Next, the width at outlet would be decreased from $2 \mathrm{~mm}$ to $1 \mathrm{~mm}$ in order to obtain the nozzle configuration.

The results showed that the accumulation of low energy fluid at near leading edge of blade tip was smaller than the case of straight slot at $40 \%$ tip chord as shown in Figure 15 (99\% span). As a result, the stability could gain more improvement $(2.070 \%)$ by inclined slot. However, flow separation at downstream of slot still be found in both cases. The quantities of the improvement and change in performances were also tabulated in Table 5 .

\section{Table. 5 Percentage of change in stall margin and performances at design point}

\begin{tabular}{|c|c|c|c|}
\hline Case & Stall Margin & Pressure Ratio & Efficiency \\
\hline $40 \%$ tip chord & $+1.976 \%$ & $-1.288 \%$ & $-0.964 \%$ \\
\hline Inclined slot & $+2.070 \%$ & $-1.472 \%$ & $-0.953 \%$ \\
\hline
\end{tabular}

*Note: (+): improvement, (-): reduction for the observed parameters

The overall performance curves (pressure ratio and efficiency) were presented in Figure 17. Furthermore, the results (performance curves) would be presented without the normalization with the choked flow in order to clearly sense the differences.

The results showed that the predicted choked flow was largely decreased from baseline by inclined slot. While it was slightly decreased when the straight slot ( $40 \%$ tip chord) was applied as shown in Figure 17. In addition, the performance drops (pressure ratio and efficiency) at near peak efficiency were found in both cases as well. However, the compressor performances (pressure ratio and efficiency) at near stall operating point would seem to be higher (better) in case of inclined slot compared to straight slot. 


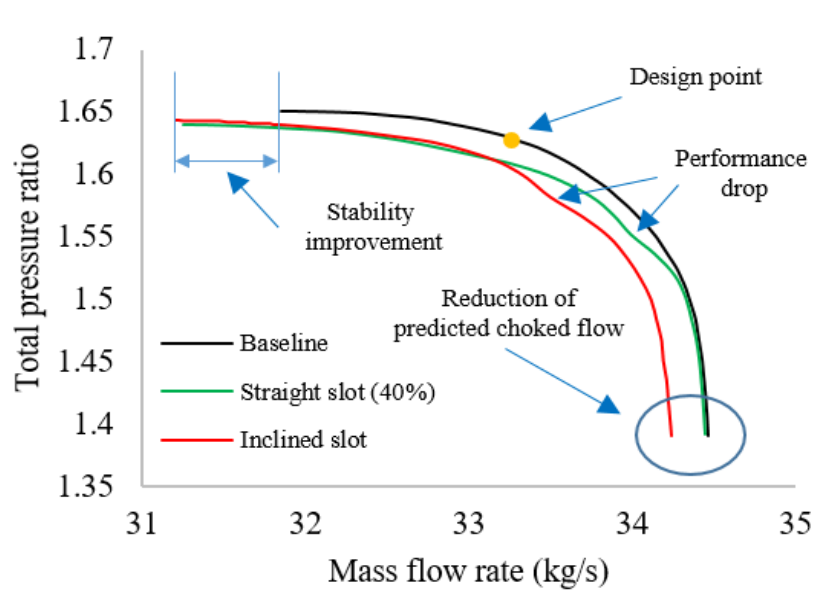

(a) Comparison of pressure ratio

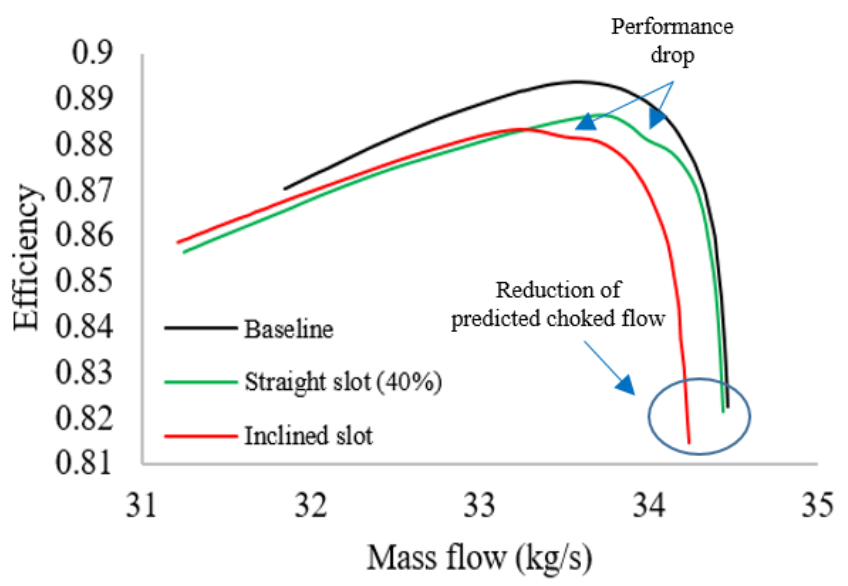

(b) Comparison of efficiency

Figure 17 Comparison of compressor performances between, baseline, straight slot $(40 \%)$, and inclined slot at design speed

The accumulation of low energy fluid through the flow passage in case of inclined slot was largely eliminated more than the straight slot (40\% tip chord) as shown by cross stream relative Mach contours in Figure 18.

Finally, even though applying this slot technique to Rotor 67 could present the capability to eliminate the accumulation of low energy fluid (flow blockage) through the flow passage (resulting in larger stable operating range), it also created the large area of low energy fluid (flow separation) on downstream of suction surface at the same time. However, the effect of this low energy fluid (flow separation) had less impact on the stable operating range.

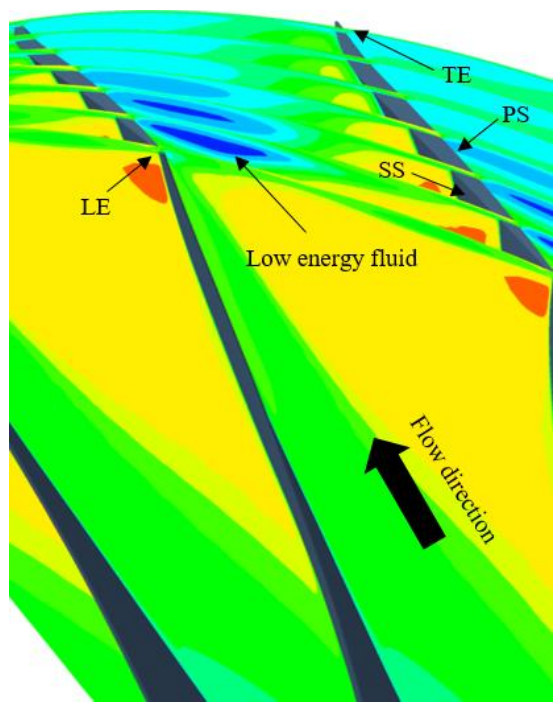

(a) Baseline rotor

Relative Mach Number

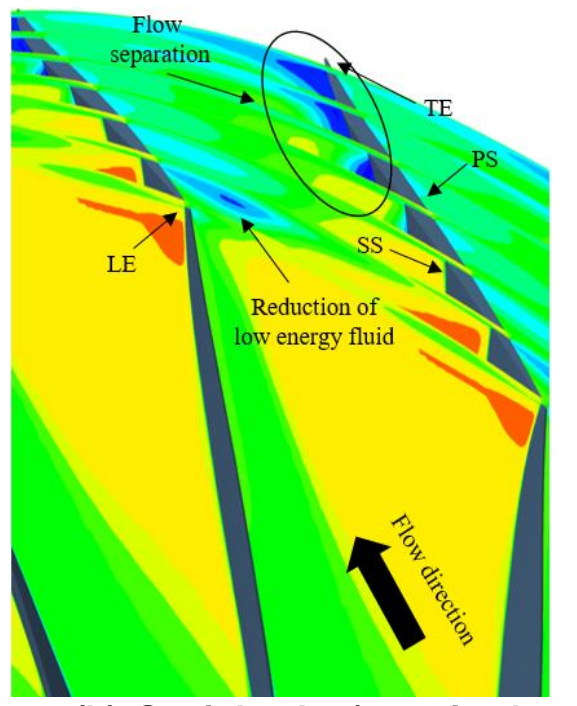

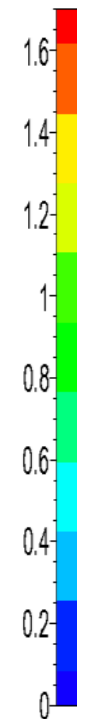

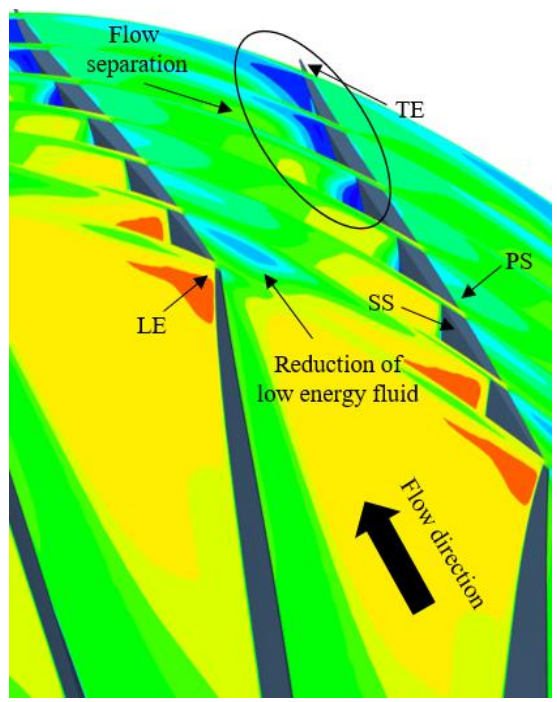

(c) Inclined slot

Figure 18 Cross stream of velocity contour at stall point for baseline model, straight and inclined slot 


\section{CONCLUSIONS}

1. For this rotor, it clearly showed that the stability range of compressor was able to gain more improvement by applying the slot technique at any locations under the area of high blade loading (at blade tip).

2. According to the investigation of slot at three main locations (near leading edge, near mid-chord, and near trailing edge), the rotor blade with slot at near mid-chord region could provide the optimum improvement. Especially, slot at $40 \%$ tip chord could provide $1.976 \%$ of stability improvement. While the lowest improvement $(0.595 \%)$ was found in case of slot at near trailing edge ( $80 \%$ tip chord) for this rotor.

3. The further improvement of stability range could be achieved by changing the slot position and its geometry to form an inclined slot with nozzle configuration. For inclined slot, the improvement of compressor stability was $2.07 \%$. The compressor performances at near stall operating point were also better than straight slot. Moreover, the predicted choked flow was largely decreased in case of inclined slot.

4. Although the low energy fluid through the flow passage could be eliminated by the slot technique, it could be created in form of flow separation under the influence of tip leakage flow and found at near trailing edge at the same time. However, it showed less impact to the stability improvement.

For the future work, the configurations of slot can be further studied to gain more improvement and also reduce the loss of efficiency and pressure ratio simultaneously. It could be achieved by the very well design for smooth flow from inlet to outlet of slot (such as creating the curvature line instead of linear line and applying the fillet at all the edges in order to reduce the loss from sharp edges).

\section{References}

Adamczyk, J. J., Celestina, M. L. and Greitzer, E. M. (1991) 'The Role of Tip Clearance in High-Speed Fan Stall', Journal of Turbomachinery, 115, pp. 1-13.

Borra, H. K. and Alone, D. B. (2015) 'STALL MARGIN IMPROVEMENT OF A SINGLE STAGE TRANSONIC AXIAL FLOW', ASME Conference Proceedings, GTINDIA2015-1211, pp. 1-13.

Fujita, H. and Takata, H. (1984) 'A study on configurations of casing treatment for axial flow compressors', Bulletin of JSME, 27(230), pp. 1675-1681.

Hu, J., Wang, R. and Huang, D. (2019) 'Improvements of performance and stability of a single-stage transonic axial compressor using a combined flow control approach', Aerospace Science and Technology. Elsevier Masson SAS, 86, pp. 283-295. doi: 10.1016/j.ast.2018.12.033.

Jain, V., Nagpurwala, Q. H. and Nassar, A. (2015) 'Effect of Partial Span Aspiration on the Performance of a Transonic Axial Compressor Rotor: A Numerical Study', International Journal of Rotating Machinery, 2015, pp. 1-13. doi: $10.1155 / 2015 / 761918$

Liu, Y. et al. (2016) 'Effect of Slot at Blade Root on Compressor Cascade Performance under Different Aerodynamic Parameters', Applied Sciences, 6(12), p. 421. doi: 10.3390/app6120421.

Lord, W. K., Macmartin, D. G. and Tillman, T. G. (2000)
'Flow Control Opportunities in Gas Turbine Engines Fluids', AIAA-Paper, (June), pp. 2000-2234.

Pérez Flores, P., Kosyna, G. and Wulff, D. (2008) 'Suppression of Performance Curve Instability of an AxialFlow Pump by Using a Double-Inlet-Nozzle', International Journal of Rotating Machinery, 2008, pp. 1-7. doi: 10.1155/2008/536850.

Ramzi, M. and AbdErrahmane, G. (2013) 'Passive control via slotted blading in a compressor cascade at stall condition', Journal of Applied Fluid Mechanics, 6(4), pp. 571-580.

Rockenbach, R. W. (1968) Single stage experimental evaluation of slotted rotor and stator blading, part 9 Final report, NAS3-7603. doi: .1037//0033-2909.I26.1.78.

Sakai, Y. et al. (2003) 'Design and Test of Transonic Compressor Rotor with Tandem Cascade', Proceedings of the international gas turbine congress, pp. 1-6.

Spotts, N. and Gao, X. (2016) 'A Comparative Study of Turbulence Models for RANS Simulations of Rotor 67', 54th AIAA Aerospace Sciences Meeting, (January), pp. 1-24. doi: 10.2514/6.2016-0608.

Strazisar, A. J. et al. (1989) 'Laser Anemometer Measurements in a Transonic Axial-flow Fan Rotor'.

Weichert, S., Day, I. and Freeman, C. (2011) 'SELFREGULATING CASING TREATMENT FOR AXIAL COMPRESSOR STABILITY ENHANCEMENT', in Proceedings of ASME Turbo Expo 2011, pp. 1-13.

Zheng, R., Xiang, J. and Sun, J. (2010) 'BLADE GEOMETRY OPTIMIZATION FOR AXIAL FLOW COMPRESSOR', Proceedings of ASME Turbo Expo 2010: Power for Land, Sea and Air, pp. 1-12.

Zhou, X. et al. (2017) 'Investigation on axial effect of slot casing treatment in a transonic compressor', Applied Thermal Engineering. Elsevier Ltd, 126, pp. 53-69. doi: 10.1016/j.applthermaleng.2017.07.165.

\section{NOMENCLATURE}

\begin{tabular}{|c|c|}
\hline $\mathbf{m}_{\text {stall,nr }}$ & $\begin{array}{l}\text { Mass flow at near stall operating point of } \\
\text { baseline rotor }\end{array}$ \\
\hline $\mathbf{m}_{\text {stall,sr }}$ & $\begin{array}{l}\text { Mass flow at near stall operating point of } \\
\text { slotted rotor }\end{array}$ \\
\hline$P_{\text {design,nr }}$ & $\begin{array}{l}\text { Pressure ratio at design mass flow of } \\
\text { baseline rotor }\end{array}$ \\
\hline $\mathbf{P}_{\text {design }, s \mathbf{r}}$ & $\begin{array}{l}\text { Pressure ratio at design mass flow of } \\
\text { slotted rotor }\end{array}$ \\
\hline $\mathbf{E}_{\text {design,nr }}$ & $\begin{array}{l}\text { Efficiency at design mass flow of baseline } \\
\text { rotor }\end{array}$ \\
\hline $\mathbf{E}_{\text {design,sr }}$ & $\begin{array}{l}\text { Efficiency at design mass flow of slotted } \\
\text { rotor }\end{array}$ \\
\hline $\mathbf{L E}$ & Leading edge \\
\hline TE & Trailing edge \\
\hline PS & Pressure surface \\
\hline SS & Suction surface \\
\hline
\end{tabular}

\section{ACKNOWLEDGMENTS}

This work is supported by the Natural Science Foundation of China (NSFC) Project (No. 51576154). 